\title{
Hyperbaric Oxygen Therapy for Reconstructive Urology Wounds: A Case Series
}

\author{
Mendy Hatibie Oley (1D ${ }^{1-3}$ \\ Maximillian Christian Oley (D) $^{3-5}$ \\ Ari Astram Adhiatma \\ Iskandar ${ }^{6,7}$ \\ Christof Toreh ${ }^{6,7}$ \\ Marcella Tirsa Tulong ${ }^{3}$ \\ Muhammad Faruk (iD ${ }^{8}$ \\ 'Plastic Reconstructive and Aesthetic \\ Surgery Division, Department of Surgery, \\ Faculty of Medicine, Sam Ratulangi \\ University, Manado, Indonesia; ${ }^{2}$ Plastic \\ Reconstructive and Aesthetic Surgery \\ Division, Department of Surgery, \\ R. D. Kandou Hospital, Manado, \\ Indonesia; ${ }^{3}$ Hyperbaric Centre Siloam \\ Hospital, Manado, Indonesia; ${ }^{4}$ Division of \\ Neurosurgery, Department of Surgery, \\ Faculty of Medicine, Sam Ratulangi \\ University, Manado, Indonesia; ${ }^{5}$ Division \\ of Neurosurgery, Department of Surgery, \\ R. D. Kandou Hospital, Manado, \\ Indonesia; ${ }^{6}$ Division of Urology, \\ Department of Surgery, Faculty of \\ Medicine, Sam Ratulangi University, \\ Manado, Indonesia; ${ }^{7}$ Division of Urology, \\ Department of Surgery, R. D. Kandou \\ Hospital, Manado, Indonesia; \\ ${ }^{8}$ Department of Surgery, Faculty of \\ Medicine, Hasanuddin University, \\ Makassar, Indonesia
}

Correspondence: Mendy Hatibie Oley Plastic Reconstructive and Aesthetic Surgery Division, Department of Surgery, Faculty of Medicine, Sam Ratulangi University, Jalan Raya Tanawangko No. 56, Malalayang Satu Barat, Malalayang, Manado, North Sulawesi, 95162, Indonesia

Fax +62 43I-863786

Email mendy.hatibie@unsrat.ac.id
Introduction: Hyperbaric oxygen therapy (HBOT) has been applied to urological wound healing because it reduces inflammation, facilitates angiogenesis through endothelial proliferation, stimulates fibroblast, lymphocyte, and macrophage activity, and exerts bactericidal effects. Thus, we present a case series of reconstructive urology wounds treated adjunctively with HBOT.

Case Report: Here, we present the cases of eight patients with urology wounds who underwent different forms of surgical reconstruction. Three patients received penile shaft silicone fluid injection with repeated infection, successful excision of a siliconoma mass, and defect closure with a full-thickness skin graft. One patient had hypospadias and multiple post-closure fistulae. Two patients had bilateral keystone flaps (post total penectomy, orchidectomy, perineotomy, and penile tumors) closed with a split-thickness skin graft (STSG). Two patients had Fournier's gangrene in their genital area, for which the wound was debrided and then closed with a STSG. All patients received HBOT after surgery with satisfying results.

Conclusion: HBOT promotes wound healing and improves graft integration in patients undergoing urological reconstructive surgery.

Keywords: hyperbaric oxygen therapy, tissue reconstruction, would healing, adjunctive treatment, urology

\section{Introduction}

Hyperbaric oxygen therapy (HBOT) is a supplemental addition to traditional medical and surgical treatments. Moreover, it is a treatment alternative for patients with underlying ischemic processes unresponsive to conventional therapy.

In the field of urology, HBOT has also been applied to some pathological conditions. Hyperoxia induced by HBOT dampens excessive inflammation, encourages angiogenesis through stimulating endothelial proliferation, enhances fibroblast activity, increases lymphocyte and macrophage activity, and confers bactericidal effects within the context of wound repair. ${ }^{1-5}$ HBOT is the only currently available therapy proven to impact wound healing. ${ }^{6}$ Thus, we present a case series of reconstructive urology wound healing treated adjunctively with HBOT. $^{7}$

\section{Patients and Methods}

The cases presented in this series are from the Division of Plastic Reconstructive and Aesthetic Surgery and Urology at Kandou Hospital and Siloam Hospital Manado. These eight cases include four diagnoses, all of whom received HBOT 
Table I Case Characteristics

\begin{tabular}{|c|c|c|c|c|c|c|c|c|c|}
\hline Patient & $\begin{array}{c}\text { Age } \\
\text { (Years) }\end{array}$ & Sex & Diagnosis & $\begin{array}{l}\text { Surgical } \\
\text { Method }\end{array}$ & $\begin{array}{c}\text { HBOT } \\
\text { Sessions }\end{array}$ & Histology & Pus Culture & Antibiotic & $\begin{array}{l}\text { IIEF-5 } \\
\text { Score }\end{array}$ \\
\hline 1 & 26 & M & Penile Siliconoma & FTSG & 5 & $\begin{array}{l}\text { Inflammation and } \\
\text { Fibrotic Tissue }\end{array}$ & Staphylococcus & Meropenem & 25 \\
\hline 2 & 27 & M & Penoscrotal Siliconoma & FTSG & 5 & $\begin{array}{l}\text { Inflammation and } \\
\text { Fibrotic Tissue }\end{array}$ & - & Ceftriaxone & 25 \\
\hline 3 & 44 & $M$ & Penoscrotal Siliconoma & FTSG & 5 & $\begin{array}{l}\text { Inflammation and } \\
\text { Fibrotic Tissue }\end{array}$ & - & Ceftriaxone & 24 \\
\hline 4 & 14 & M & Hypospadias & $\begin{array}{c}\text { Fistula } \\
\text { closure with } \\
\text { flap }\end{array}$ & 5 & - & - & Cefotaxime & - \\
\hline 5 & 32 & $M$ & Penile Papilloma & $\begin{array}{l}\text { Keystone } \\
\text { Flap }\end{array}$ & 5 & SCC & Staphylococcus & Meropenem & - \\
\hline 6 & 46 & $M$ & Condyloma Acuminata & $\begin{array}{l}\text { Keystone } \\
\text { Flap }\end{array}$ & 5 & Condyloma & Staphylococcus & Meropenem & - \\
\hline 7 & 48 & M & $\begin{array}{l}\text { Fournier's Gangrene } \\
\text { and Diabetes Mellitus }\end{array}$ & $\begin{array}{c}\text { Bilateral } \\
\text { inguinal flap }\end{array}$ & 6 & - & Staphylococcus & Meropenem & 21 \\
\hline 8 & 61 & $M$ & Fournier's Gangrene & STSG & 6 & - & Staphylococcus & Meropenem & 20 \\
\hline
\end{tabular}

Abbreviations: IIEF-5, International Index of Erectile Function; M, male; FTSG, Full-thickness skin graft; STSG, split-thickness skin graft; SCC, squamous cell carcinoma.

in addition to a histological examination, culture, and IIEF-5 scoring (Table 1). Within 1 week of surgery, HBOT was delivered in five $60-90-$ min sessions in a monoplane chamber at 2-2.4 absolute atmospheres (ATAs).

\section{Case Presentation}

We present eight cases involving the surgical reconstruction of urology wounds adjunctively treated with HBOT.

\section{Case I}

Male, 26 years old, with a history of penis shaft silicone liquid injection (Figure 1A). After 3 years, he came to our Plastic Surgery Division with the main complaint of a hardening swollen penis with recurrent infection and recurrent lymphadenitis in both inguinal regions. The patient had difficulty urinating because of a protruding mass into the penis and feeling pain upon morning erection. The penis elicits severe pain when erecting for sexual intercourse. The physical examination revealed that the skin on the distal region of his penis was swollen with a diameter of roughly $5 \mathrm{~cm}$ when not erect, with the consistent expression of a circular solid mass. The patient already had an incision at the distal area of a circular paraffinoma mass to release the pressure on the glands by another paramedic and cannot urinate because of the infection of the incision area. The patient was referred to our division with a catheter and infection surrounding the gland area due to the excision. The patient was scheduled for paraffinoma mass excision and defect closure with FTSG. Excision was performed from the penile-pubic junction proximally to the distal shaft up to $0.3 \mathrm{~mm}$ from the glands (Figure 1B). The depth of excision did not cross the dartos fascia. The graft was taken from the left inguinal region and closed primarily using 5-0 polyglactin braided and 5-0 polypropylene sutures. The FTSG was placed on the raw surface area of the penile shaft in a spiral or circular pattern in a single graft sheet (Figure 1C). Using a 5-0 vicryl suture, the skin graft is connected at the coronal margin of the glans penis, pubic skin edge, and between the skin grafts. Quilt sutures from the FTSG to the dartos fascia were used to ensure the skin graft could not move or be crippled. The penis was a fixation with the dressing in an erect position. We used a silicone foley catheter because the patient was on bed rest for 2 weeks to ensure the skin graft would take and get other drugs such as antibiotics, analgesics, albumin, and vitamins. The patient was treated with HBOT as an adjunctive therapy. After five sessions of 2.0 ATA HBOT, the graft took successfully (Figure 1D). The 

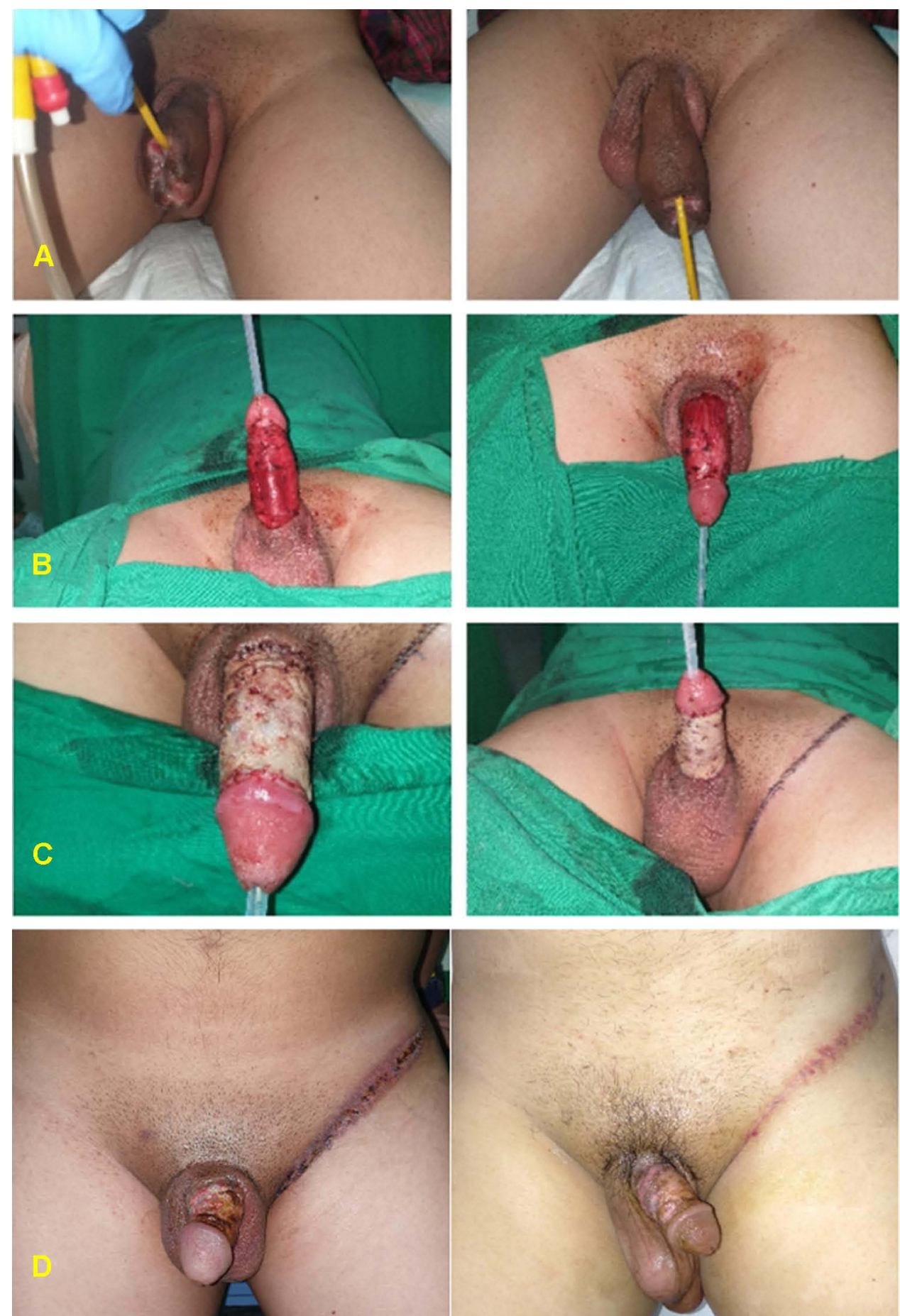

Figure I (A) Penile paraffinoma with infection at the swollen preputium area. (B) Excision of the paraffinoma. (C) Post penile resurfacing with FTSG in a one-sheet spiraling pattern. (D) 8 weeks after the fifth session of HBOT.

follow-up at 6 months showed promising results; the patient only complained of slight itching in the postoperative area, which was treated with moisturizer at the donor and recipient sites. There was no infection, and the patient's IIEF-5 score of 26 indicated no erectile dysfunction. The patient was happy with the result.

\section{Case 2}

Male, 27 years old, with a history of injecting traditional oil medication into his penis shaft following recurrent infection. The patient reported that his penis had a swollen, hard, heavy feeling and difficulty urinating because of the fibrotic tissues (Figure 2A). He also 


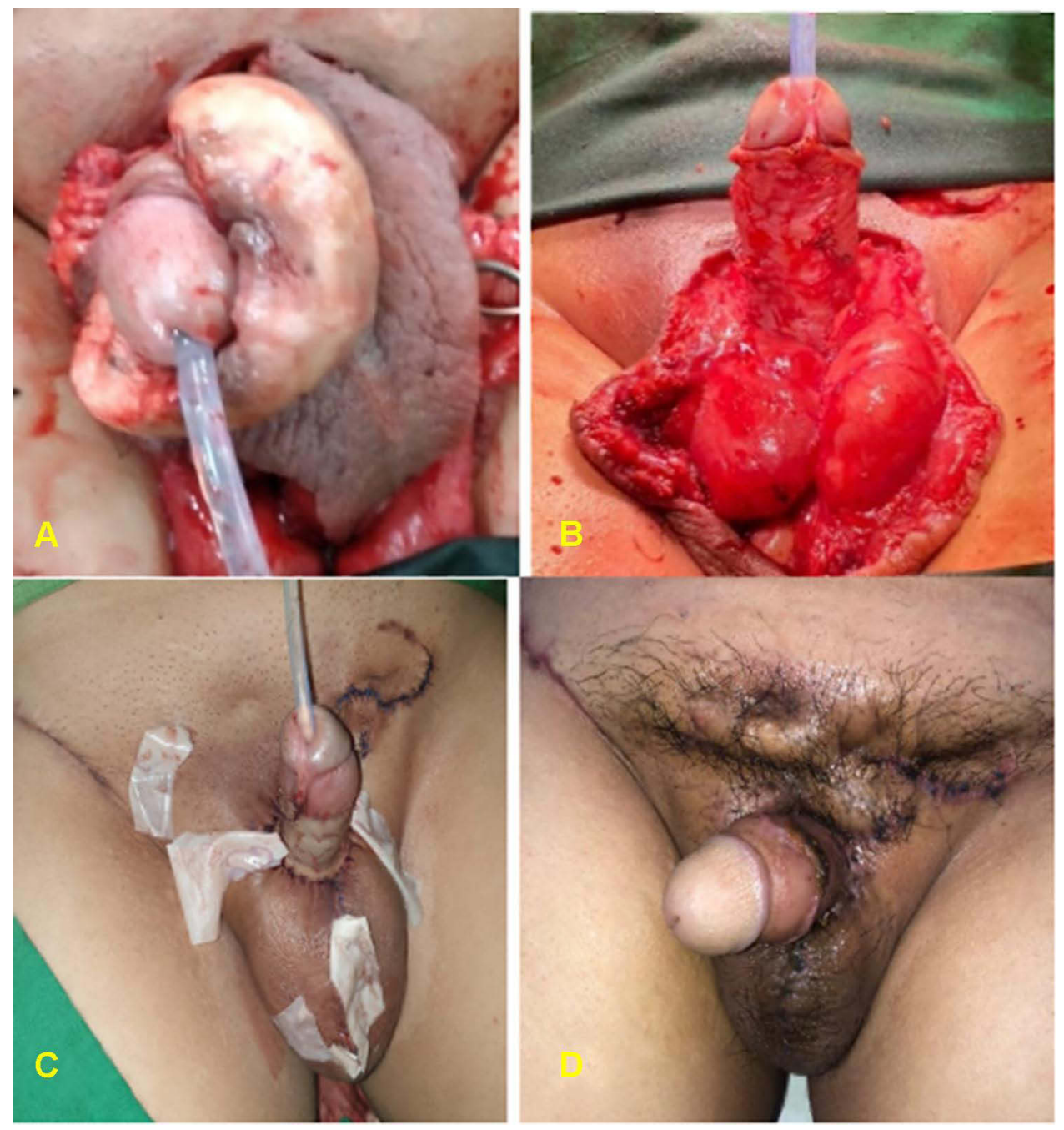

Figure 2 (A) Pubic, penile, and scrotal paraffinoma. (B) Excision of the paraffinoma mass. (C) Post reconstruction of the pubic and scrotal areas and resurfacing the shaft penile defect with one-sheet spiraling FTSG. (D) 3 weeks after the fifth session of HBOT.

experienced pain, especially during his morning erection. The patient had a paraffinoma mass excised by our colleague from the Urology Division, and we closed the defect with FTSG. Intraoperatively, we found a paraffinoma mass along the penile shaft that had already infiltrated around the pubic and scrotal area (Figure 2B). The pubic and scrotal area was reconstructed with healthy surrounding tissue and left Penrose drains (Figure 2C). We took the FTSG donor from the right inguinal to cover the penile shaft defect with a spiraling pattern described in case no. 1. After surgery, the patient also received other drugs such as antibiotics, analgesics, albumin, and vitamins. The patient was treated with HBOT as adjunctive therapy 1 week after the surgery. After five sessions of 2.0 ATA HBOT, the graft was considered a success (Figure 2D). The patient was discharged from the hospital on the 14th postoperative day and with weekly follow-up. We used skin moisturizer for the scar at the donor and recipient sites. There was no complaint about the erection or sexual function.

\section{Case 3}

Male, 44 years old, referred to our division from another island with a huge mass on his penis and scrotum. He was injected with olive oil several times a couple of years ago. Due to the paraffinoma mass reported a heavy feeling in his scrotal and penile areas (Figure 3A). He also had repeated blisters at the bilateral inguinal that caused him pain and made walking difficult. He complained of pain upon erection, and the swollen mass rendered him unable to achieve satisfactory sexual intercourse. He could still urinate but had a trapped feeling about the paraffinoma 

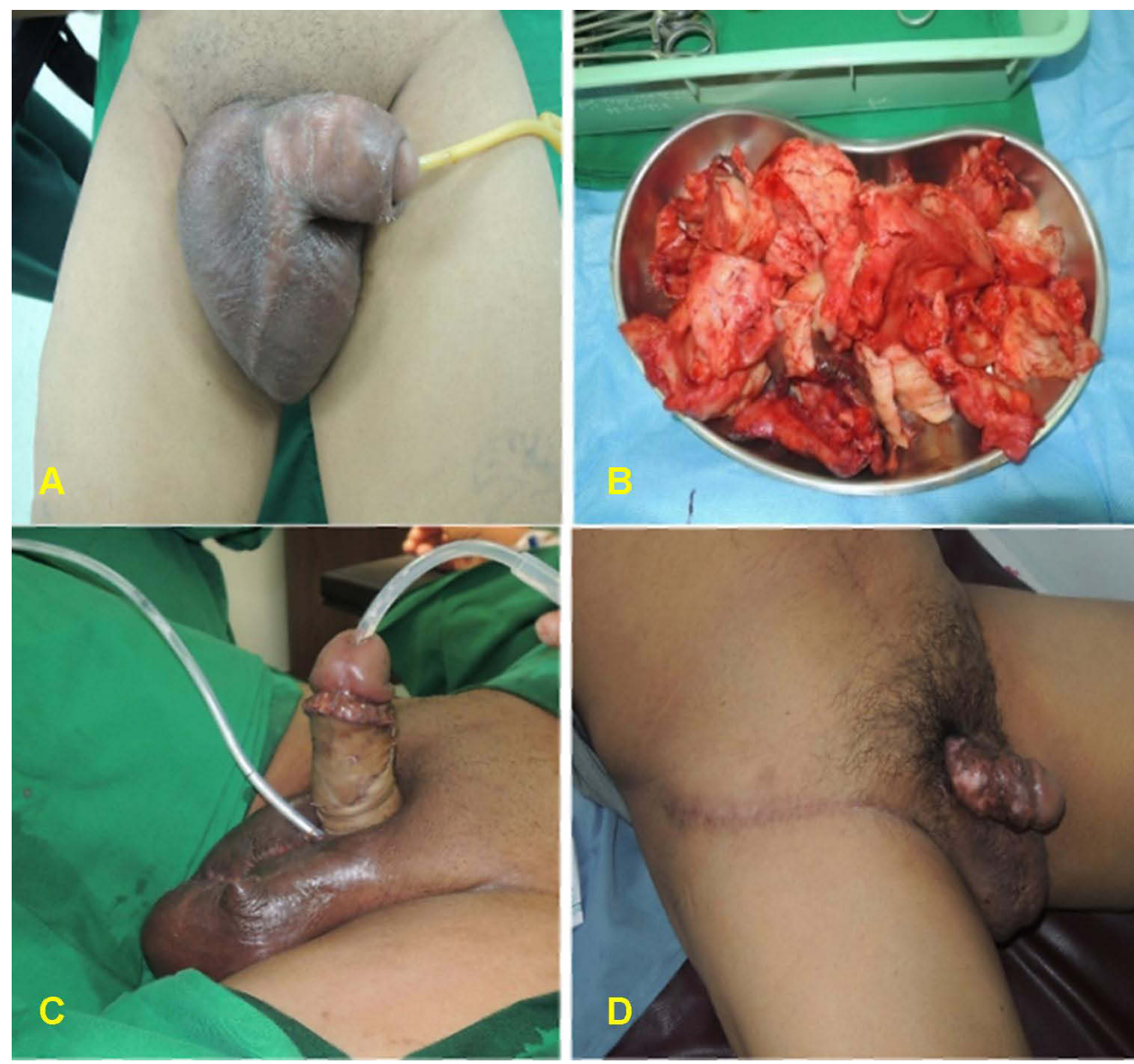

Figure 3 (A) Penile paraffinoma. (B) Paraffinoma mass excision. (C) The penis was resurfaced with one-sheet spiraling FTSG. (D) 6 weeks post reconstruction of the penoscrotal area, after five sessions of HBOT.

mass around the penoscrotal area. The mass excision was performed by our colleagues from the Urology Division to the penis and scrotal area. The excised paraffinoma mass was firm, yellow in color, and almost 1 kilogram in weight (Figure 3B). The scrotal area was reconstructed with the healthy surrounding tissue and left to vacuum drain for 3 days. The penis was resurfaced with a one-sheet spiraling FTSG from the right inguinal (Figure 3C). The surgical technique was the same as cases no. 1 and 2. The patient also received other drugs such as antibiotics, analgesics, albumin, and vitamins. One week after the surgery, the patient had five HBOT sessions with 2.0 ATA (Figure 3D). The patient was discharged from the hospital on the 14th postoperative day with outpatient follow-up twice per week. After 1 year, the patient had no complaints and was satisfied with the surgical results.

Soft tissue filler is a critical component of aesthetic dermatologic surgery. In soft tissue augmentation, a variety of temporary and permanent filler compounds have been used. Paraffin, Vaseline, and liquid injectable silicone are the most commonly used. Extruded polytetrafluoroethylene and Silastic (strong silicone) implants are the simplest permanent filler fabrics approved for use in the US In the past, liquid silicone was utilized for permanent soft tissue augmentation, but the FDA has not approved the forms of liquid silicone available for medical usage in the US. ${ }^{8}$ Liquid silicone is injected intradermally and subcutaneously in animals and people since it is predictable, self-restricted, nonirritating, and nearly noninflammatory. It can be visualized under the microscope as dispersed vacuolization or encapsulated by collagen deposition and fibrosis. ${ }^{9}$ Around the silicone droplets, phagocytes and other large cell responses are occasionally detected. The tissue enlargement when silicone is injected is caused by collagen deposition and fibrosis. ${ }^{9}$ In these paraffinoma patients, fibrotic tissue almost surrounded the penile area, and removing the fibrous tissue without damaging the surrounding tissue was challenging. Despite its reputation as a chemically inert material, liquid silicone has been associated with severe inflammatory reactions, 
including tissue damage. When substances are injected into the penis for augmentation, granulomatous and fibrotic reactions occur in the subcutaneous fat region, resulting in the formation of a lipogranuloma, which appears as a firm disfiguring subcutaneous mass with surrounding skin fibrosis and thickening, giving the impression of a larger penis. Pain, erythema, foreign object reaction, ecchymosis, cellulitis, tissue damage, scarring, ulceration, and even discomfort for their sexual partner are some of the local complications. ${ }^{10}$ We can use several methods to treat paraffinoma, including a one-sheet full-thickness skin graft. This technique has some advantages, namely, starting from a not extensive scar, a lower secondary contraction rate than a split-thickness skin graft, and a reduced occurrence of hypertrophy and keloids. ${ }^{11}$

\section{Case 4}

Male, 14 years old, with hypospadias and post-closure fistulae with flap (Figure 4A). After five sessions of 2.0-ATA HBOT, the fistulae reduced in size and number. Post-treatment, there was only one pin-point fistula (Figure 4B).

The purpose of hypospadias surgery is to correct the curvature of the penis, returning it to its original position; however, the occurrence of a fistula is an obstacle to the success of this procedure. The incorporation of urethral mucosa or neo-urethra in ventral repair and fast migration of urethral mucosa and skin epithelium into suture tracts is the mechanism of UCF formation, which is frequently caused by infection, ischemia, or a combination thereof. Local infection is the most common cause of a fistula. Within the first two weeks after surgery, infection sets in, contributing considerably to the high percentage of fistulae that develop within the first month; ${ }^{12}$ this is when HBOT plays an important role in preventing infection. There are several ways to repair UCFs, but those that use mobilized flaps to patch the fistula have better outcomes. In this patient, we used a flap-based surgical method. After that, to ensure flap survival, the patient received five sessions of HBOT because an erect penis, especially in the morning, can cause flap failure, resulting in the risk of recurrent fistulae. The patient also received other drugs such as antibiotics, analgesics, albumin, and vitamins.

\section{Case 5}

Male, 32 years old with bilateral keystone flap (post total penectomy), orchidectomy, perineotomy due to giant penile papilloma (Figure $5 \mathrm{~A}$ and $\mathrm{B}$ ). The patient had wound dehiscence on the middle of the bilateral keystone flap that (Figure 5C) occurred 1 week after the first surgery caused by an infection and decreased hemoglobin and albumin levels. The pandemic presented a challenge for us as surgeons because it was challenging to find blood donors who were not infected with SARS-CoV2; therefore, it required additional time to increase hemoglobin and albumin levels. After 2 weeks, we performed
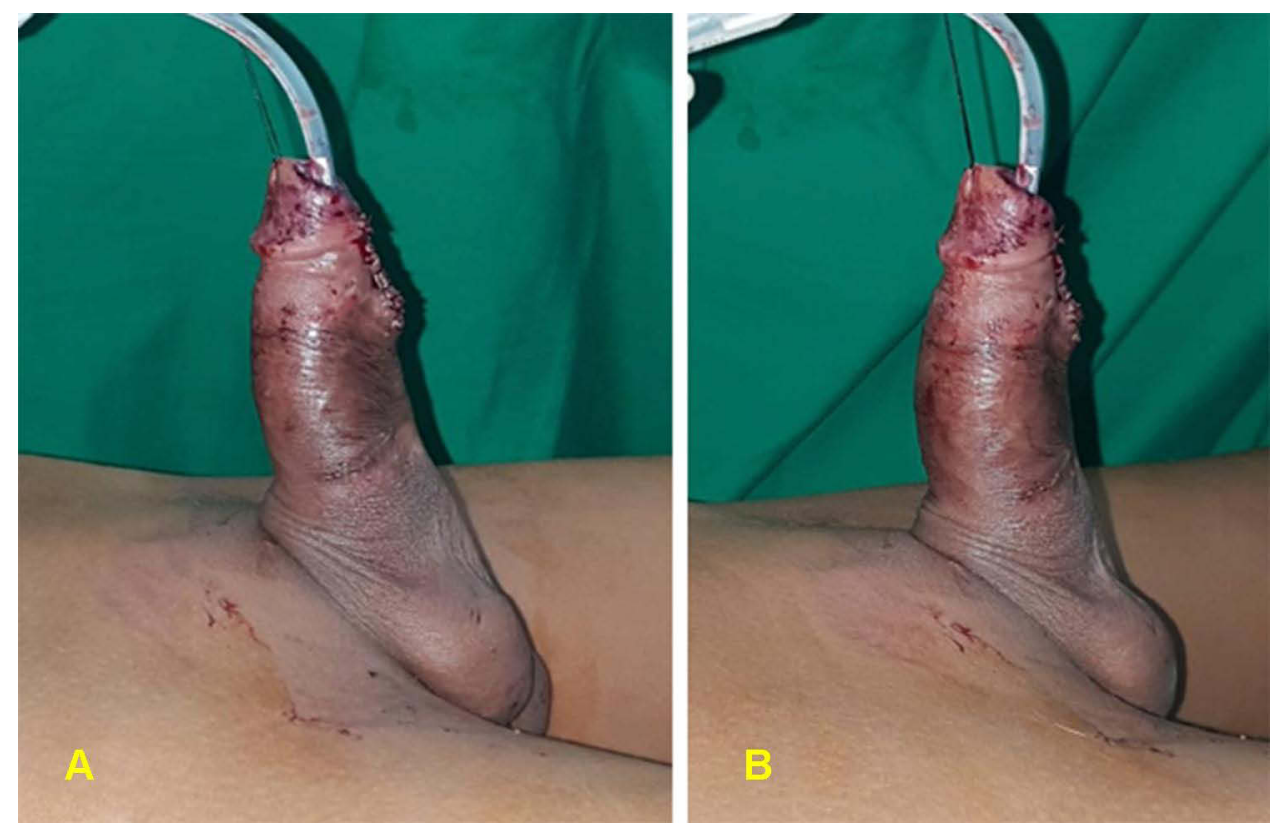

Figure 4 (A) Pre-fistula closure. (B) Post-fistula closure. 

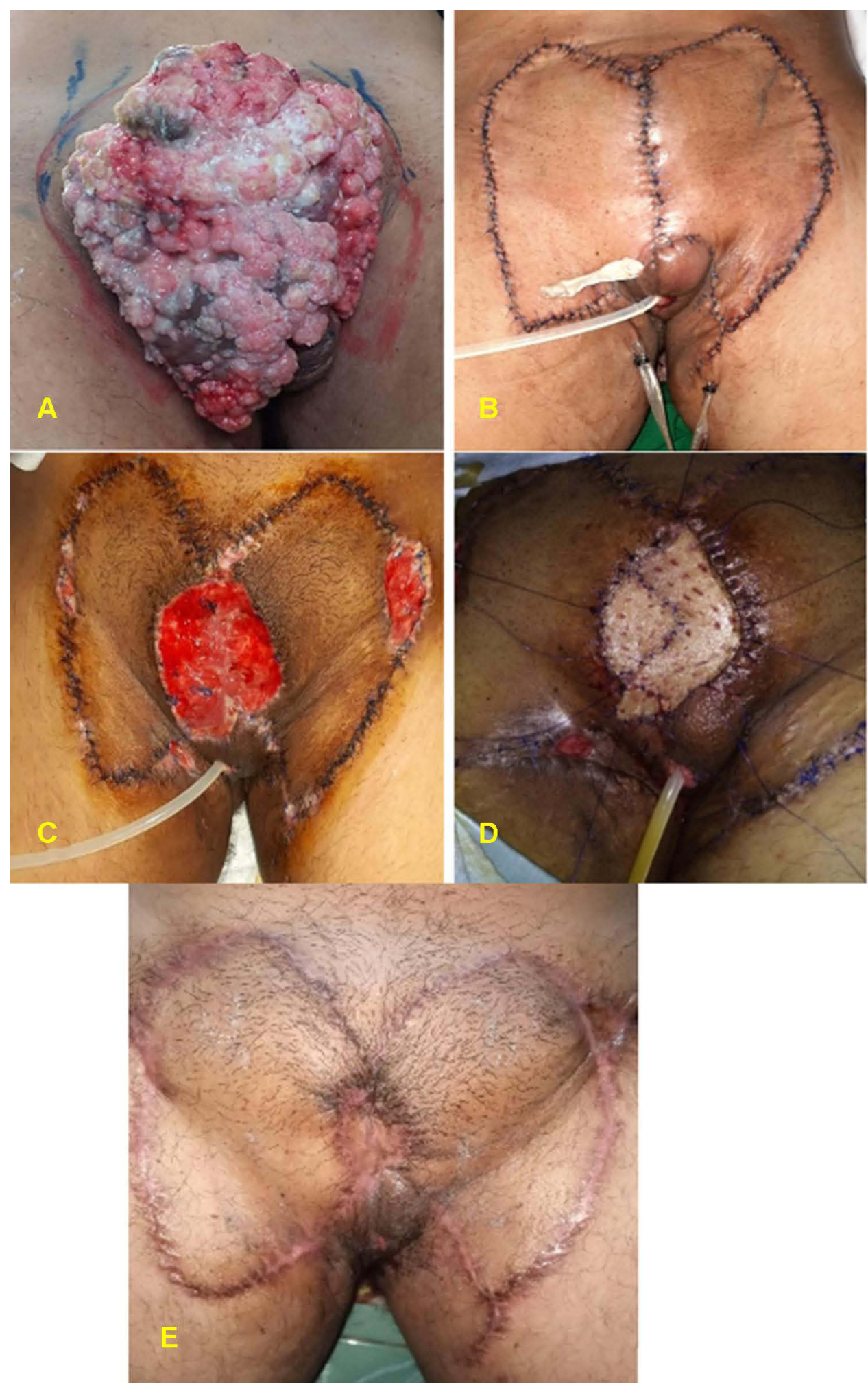

Figure 5 (A) Giant penile papilloma. (B) Post bilateral keystone flap. (C) Wound dehiscence and secondary infection. (D) Defect closure with STSG. (E) 8 weeks post five sessions of HBOT.

the second operation, and the defect was closed with STSG (Figure 5D). To prevent a repeat of this complication, the patient was given other drugs such as antibiotics, analgesics, albumin, vitamins, and HBOT as an adjunct therapy to protect the wound from infection and ensure the skin graft's successful integration. The function of HBOT 
is to prevent inflammation and accelerate wound healing. After 2 weeks and five sessions of 2.0 ATA HBOT, the patient showed improved wound closure, and the graft was considered a success (Figure 5E). The patient was also undergoing chemotherapy.

\section{Case 6}

Male, 46 years old, with complaints of a lump in his penis. The lump first appeared 5 years ago and was removed by another surgeon, but the lump has reappeared in the last 2 years. The lump started to grow like cauliflower (Figure 6A). A tumor encircling the entire penis and scrotum was detected upon physical examination, while the glans penis was free of the lesion. Wide excision of the penile mass was performed with total penectomy, orchidectomy, and perineostomy (Figure 6B). The wound was closed using the Keystone flap technique involving an elliptical incision pattern (Figure 6C), after which the flap is incised on all sides and bluntly dissected down to the fascia. The donor tissue was taken from the right inguinal. A drain was placed beneath the flap. The incisional biopsy revealed squamous cell carcinoma. 2 weeks after the surgery, the patient was given five HBOT sessions (Figure 6D). After the surgery and HBOT sessions, the patient was undergoing chemotherapy.

Penile carcinoma is a type of invasive epithelial tumor that develops on the penis' skin or mucosa. There are many causes and risk factors for penile cancer, but the
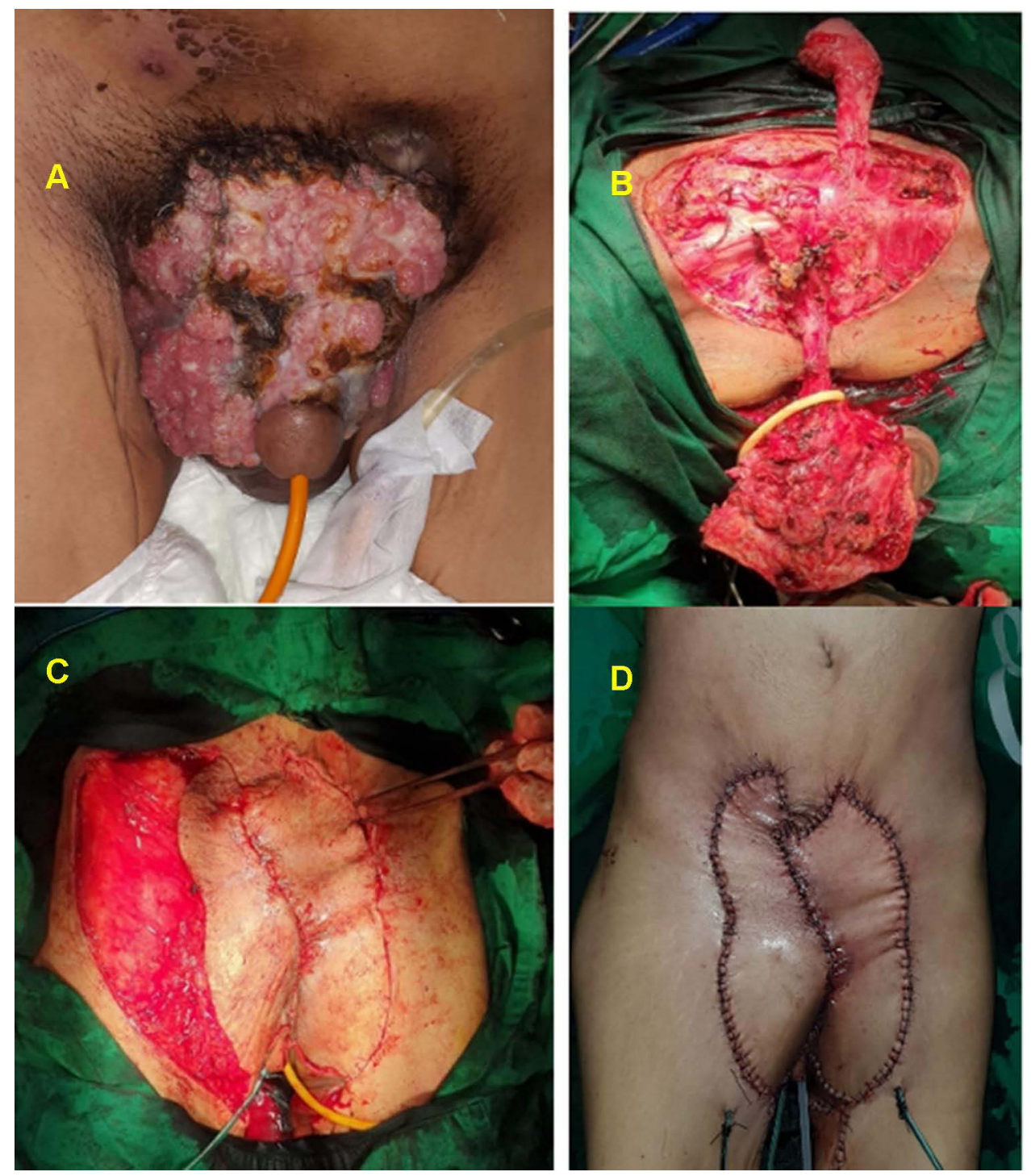

Figure 6 (A) A 46-year-old male presented with squamous cell carcinoma on his genitalia. (B) Intra-operative excision of the mass with total penectomy, orchidectomy, and

perineostomy. (C) Closure of the inguinal defect with a keystone flap in a mirror fashion. (D) Post-operative, after five HBOT sessions. 
most common cause is human papillomavirus (HPV). The glans penis, coronal sulcus, and foreskin are common sites for penile cancer. Invasive ulcerative penile cancer can harm the root of the penis, causing it to dilate and leading to the organ's spontaneous amputation. It can even affect the lymph nodes in the inguinal region. ${ }^{13}$ The mechanism of HPV infection has several pathways: the disruption of tumor suppressor gene p53 and pRB proteins. Diagnosing cancer requires pathological histological examination. Histologically, penile squamous cell carcinoma has several subtypes, and these have variable rates of metastasis. ${ }^{14}$ Penile cancer surgery is performed using several methods depending on the size of the tumor. One such is the Mohs surgery technique, in which the tumor is excised to the bottom layer or until the tumor tissue is no longer present, followed by wound closure surgery. ${ }^{15}$

Keystone flap is the most widely used method for closing large defects. The main advantage of this approach for post-tumor skin reconstruction is its simplicity since it may be performed in one stage with no donor site morbidity, allowing for reconstruction with compatible tissues. Wound dehiscence can be defined as the failure of partial or complete wound closure caused by several factors, either pre-or post-surgery. Anemia, hypoalbuminemia, starvation, and other conditions like infection are linked to a higher incidence of wound dehiscence. ${ }^{16}$ In some cases, anemia and hypoalbuminemia are the most significant preoperative risk factors for wound dehiscence, while wound contamination is the most significant postoperative risk factor. ${ }^{16,17}$ In this patient, after the first operation, there was a decrease in hemoglobin and albumin levels related to the wound healing process, which requires oxygen vascularization and adequate protein levels.

\section{Case 7}

Male, 48 years old, with complaints of pain, swelling, and pus discharge from his genital region, and the wound had started to smell because of a bacterial infection. Initially, blisters arose due to friction from the patient's clothing that became infected. Local examination revealed erythematous, swelling, and pus in the scrotum, and the penile body was gangrenous with necrotic skin (Figure 7A). The patient had diabetes mellitus, which makes wound healing more difficult. We extensively debrided the patient, and a sample was collected for analysis. While waiting for the results, the patient was given three HBOT sessions $(2.0$ ATA pressure for 90 minutes each). The culture results indicated the presence of staphylococcal bacteria, for which the patient was given Meropenem. We closed the defect with a bilateral inguinal flap and left Penrose drains (Figure 7B). The patient was given three sessions (2.0 ATA pressure for 90 minutes each) of HBOT to speed up the wound healing process and control the infection. Four weeks after the surgery and with six sessions of HBOT, the flap was vital with no signs of secondary infection, the edema was resolved, the patient had no complaints of pain, and was satisfied with the results.

\section{Case 8}

Male, 61 years old, complained of pain and swelling in his genital area (Figure 8A). Local examination revealed found swelling, erythematous, and a small patch of necrotic skin on the scrotum. The patient has diabetes and presented with a very odiferous wound due to infection of the penoscrotal area. We debrided the wound, and his metabolic status was controlled with three sessions of HBOT before closing the defect with STSG, followed by
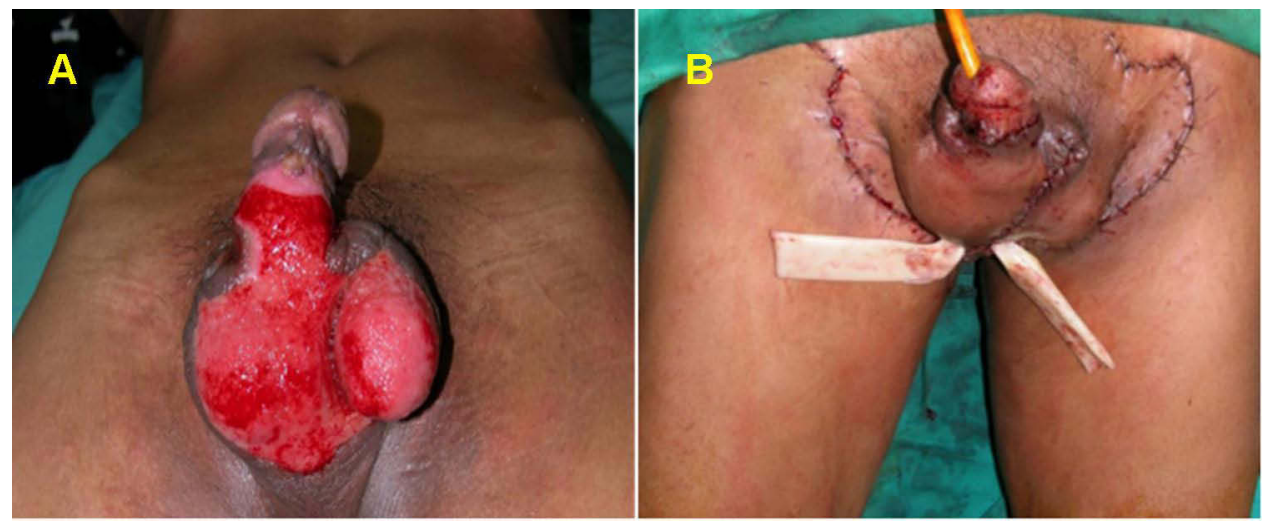

Figure 7 (A) A 6I-year-old man with Fournier's gangrene on the scrotum and penile body after debridement. (B) Closure of the penoscrotal defect with a bilateral inguinal flap and left Penrose drains. 


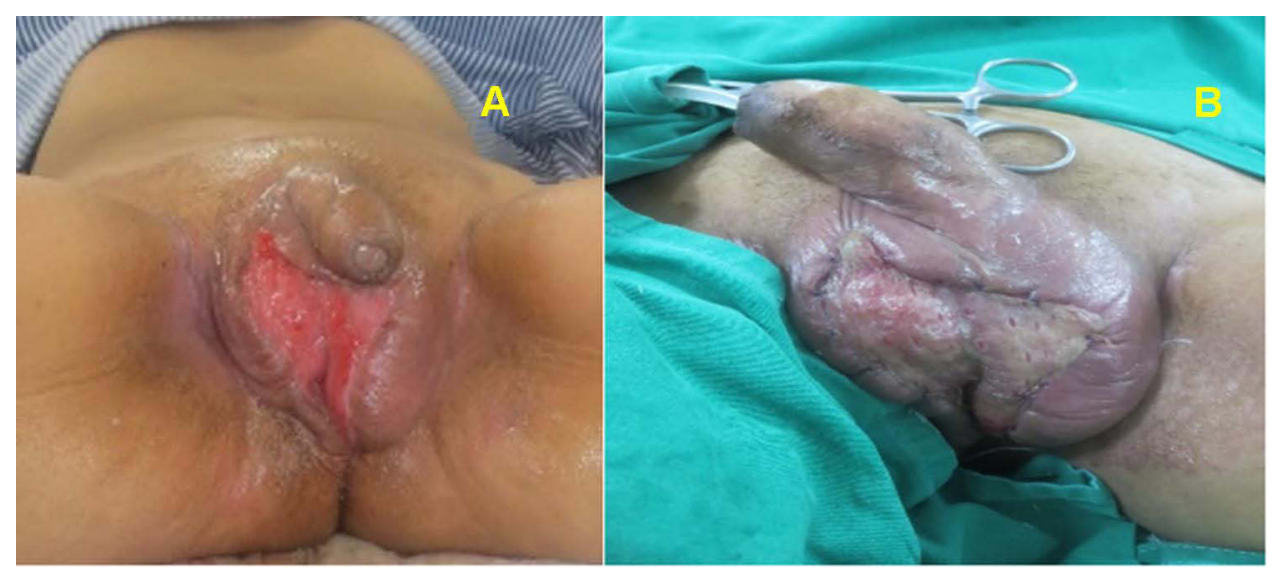

Figure 8 (A) Male 48 years old with Fournier's gangrene on his scrotum after debridement. (B) 7 days post STSG, after six sessions of HBOT.

three HBOT sessions in the 7 days post skin graft (Figure 8B). Pus culture results indicated the presence of staphylococcal bacteria, and Meropenem was prescribed for antibiotic therapy according to the sensitivity test.

Fournier's gangrene is necrotizing fasciitis arising from infection caused by aerobic and anaerobic microorganisms that affect the perineal area and can spread to the abdomen. The risk factors include diabetes mellitus, the use of steroid drugs, alcoholism, and disorders related to the immune system. ${ }^{18}$ The initial treatment for Fournier's gangrene is debridement to prevent the infection from getting worse, followed by the administration of antibiotics against specific microorganisms. However, the low blood supply to the infected area can substantially slow the wound healing process. In this case, HBOT can help to accelerate wound healing by increasing oxygen levels and encouraging fibroblasts proliferation and tissue regeneration. Many cases of using HBOT as adjunctive therapy for Fournier's gangrene have been described. ${ }^{19,20}$

In the case of Fournier's gangrene, HBOT can be particularly beneficial; namely, the high oxygen concentration helps repair hypoxic tissues and cells, inhibits the growth of microorganisms, and accelerates wound healing. ${ }^{21}$ By enhancing the generation of reactive oxygen species (ROS), HBOT serves as a bactericide and/or bacteriostatic agent against anaerobic bacteria and restores the bactericidal activity of leukocytes in hypoxic wounds. ${ }^{22}$ In complex cases, such as those with diabetes mellitus comorbidity, the combination of adjunctive therapies such as VAC and HBOT has yielded satisfactory results in infection management. ${ }^{23,24}$

\section{Discussion}

HBOT delivers pressurized oxygen to increase tissue oxygen levels. Oxygen is administered at levels higher than atmospheric pressure to ensure that the oxygen is delivered to the infected area, enhancing the body's natural healing processes. HBOT stimulates signal transduction cascades by increasing reactive oxygen and nitrogen species. In response, tissues release prostaglandins, nitric oxide, and cytokines that initiate pathophysiological responses toward wounds, surgery, and infections. ${ }^{25}$ For example, supplying $100 \%$ pressurized oxygen increases serum VEGF levels, accelerating wound healing. ${ }^{26}$

In this case, series wound defects were closed using STSG, FTSG, and skin flaps and then treated with HBOT adjunctively. Systemically administered oxygen relies on the vasculature to deliver the oxygen to the tissues. Thus, it may efficiently increase the $\mathrm{pO}_{2}$ of skin at the wound perimeter. The correction of wound $\mathrm{pO}_{2}$ is a fundamental issue that alone may trigger wound healing. During wound healing, the elevated metabolic needs characteristic of the proliferative phase increase oxygen demand. During the inflammatory phase of wound healing, oxygen deprivation or hypoxia is prevalent and signals macrophages to release cytokines to recruit the other cell types required for the next phase. ${ }^{4,27,28}$ More importantly, approaches that correct wound $\mathrm{pO}_{2}$ can profoundly influence other therapies, such as growth factor responsiveness and graft acceptance. $^{3,29}$

For wound healing, grafts and flaps are used in a variety of surgical applications. The flap is typically used to repair wound defects with a random or axial pattern. The most common complication of flap or graft failure is ischemia due to a lack of oxygen that ultimately 
inhibits wound healing. ${ }^{30}$ The graft healing process is fundamentally different for flaps in that there are no blood vessels directly supplying the graft, which receives all necessary nutrients from plasma imbibition. HBOT can salvage compromised grafts/flaps and improve composite graft survival and effective size, skin graft outcomes, and flap survival. The mechanisms underlying these beneficial effects include increased oxygenation, improved fibroblast function, neovascularization, and the amelioration of ischemia-reperfusion (IR) injury. ${ }^{29}$

A similar study in France reported less graft area contracture $(9 \%$ vs $26 \%, \mathrm{p}=0.04)$ and graft failure $6 \%$ vs $28 \%, p=0.03$ ) in those who received HBOT after reoperative hypospadias repair using oral mucosal autografts compared with those who did not receive HBOT. ${ }^{6}$ Similarly, in a study of pediatric patients with hypospadias cripple, all patients in the HBOT group had good graft take and no graft contraction. ${ }^{31}$ In contrast, $43 \%$ of the patients in the control group had graft contraction. In our cases of hypospadias, those treated with adjuvant HBOT showed favorable outcomes with multiple closed fistulae.

HBOT also indirectly improves graft survival by controlling infection, such as soft tissue infections caused by anaerobic bacteria, such as gas gangrene, necrotizing fasciitis, and Fournier's gangrene. The therapeutic effect of HBOT on infection involves directly suppressing the growth of anaerobic bacteria (eg, clostridia) and stimulating leukocyte-induced bacterial lysis. ${ }^{32,33}$ Moreover, HBOT accelerates the proliferation and migration of epithelial cells, thus encouraging new tissues to form at the wound's surface and expediting healing even for complex wounds. ${ }^{34,35}$ A review of 34 cases of Fournier's gangrene in Europe concluded that HBOT should be used as adjuvant therapy, when available, due to its bactericidal and bacteriostatic effects against this severe necrotizing infection. ${ }^{19}$

HBOT also accelerates wound healing by stimulating angiogenesis in cases of penile amputations. Three different cases of self-inflicted penile amputations showed accelerated wound healing after incorporating HBOT into the skin grafting treatment regimen. ${ }^{36-38}$ Furthermore, in one of these studies, Pseudomonas infection was present on the dorsal surface of the penis, and the combination of skin grafting, antibiotic treatment, and HBOT rapidly cleared the infection. ${ }^{37}$

\section{Conclusions}

HBOT promotes wound healing and graft integration in patients undergoing the surgical reconstruction of urology wounds.

\section{Ethics Approval and Informed Consent}

All procedures performed in this report involving human participants were in accordance with the ethical standards of the institutional and/or national research committee and with the 1964 Helsinki declaration and its later amendments or comparable ethical standards. Written informed consent was obtained from all patients, or parental/legal guardian in the case of the youngest patient, discussed in the manuscript to publish the case details and any accompanying images. The study is exempt from ethical approval in our institution.

\section{Acknowledgments}

We would like to express our appreciation to Deanette Michelle R. Aling M.D for her contribution to the critical writing of this case series.

\section{Author Contributions}

All authors made a significant contribution to the work reported, whether that is in the conception, study design, execution, acquisition of data, analysis, and interpretation, or in all these areas; took part in drafting, revising, or critically reviewing the article; gave final approval of the version to be published; have agreed on the journal to which the article has been submitted; and agree to be accountable for all aspects of the work.

\section{Disclosure}

The authors declare that they have no potential conflicts of interest for this work.

\section{References}

1. Xie D. The role of hyperbaric oxygen therapy in andrology. Int Arch Urol Complicat. 2017;3:13-16. doi:10.23937/2469-5742/1510022

2. Tanaka T, Minami A, Uchida J, Nakatani T. Potential of hyperbaric oxygen in urological diseases. Int $J$ Urol. 2019;26:860-867. doi:10.1111/iju. 14015

3. Gordillo GM, Sen CK. Revisiting the essential role of oxygen in wound healing. Am J Surg. 2003;186:259-263. doi:10.1016/S00029610(03)00211-3

4. Buganza Tepole A, Kuhl E. Systems-based approaches toward wound healing. Pediatr Res. 2013;73:553-563. doi:10.1038/pr.2013.3

5. André-Lévigne D, Modarressi A, Pepper MS, Pittet-Cuénod B. Reactive oxygen species, and NOX enzymes are emerging as key players in cutaneous wound repair. Int J Mol Sci. 2017;18(10):2149. doi:10.3390/ijms 18102149

6. Hampson NB, Holm JR. Hyperbaric oxygen therapy improves oral graft take in hypospadias staged tubularized autograft reoperations. J Urol. 2020;203:421-422. doi:10.1097/JU.0000000000000608

7. Agha RA, Borrelli MR, Farwana R, Koshy K, Fowler AJ, Orgill DP. The PROCESS 2018 statement: updating consensus Preferred Reporting Of CasE Series in Surgery (PROCESS) guidelines. Int J Surg. 2018;60:279-282. doi:10.1016/j.ijsu.2018.10.031 
8. Sepehripour S, Filobbos G, Drake M, Orlando A. Scrotal siliconoma: complications of an unapproved substance to an uninformed public. Case Reports. 2013;2013:bcr2012008122-bcr2012008122. doi:10.11 36/bcr-2012-008122

9. Dachlan I. Penile granuloma caused by liquid silicone injection. J Med Sci. 2007;39:53-58.

10. Manap AHA, Rashid AA, Devaraj NK, Fathi NQFNH. A presentation of penile siliconoma in primary care after a dubious implant injection: a case report, Malaysian. J Med Health Sci. 2019;15:170-172.

11. Prasetyono TOH. One-sheet spiraling full-thickness skin graft for penile resurfacing after paraffinoma excision. Med J Indones. 2011;222. doi:10.13181/mji.v20i3.450

12. Jumbi T, Shahbal S, Mugo R, Osawa F, Mwika P, Lessan J. Urethrocutaneous fistula after hypospadia repair: a single-institution study. Ann Afr Surg. 2019;16. doi:10.4314/aas.v16i2.4

13. Dobiáš M, Marecová K, Vránová K, Handlos P. Penile carcinoma a rare cause of sudden death. Forensic Sci Med Pathol. 2019;15:506-508. doi:10.1007/s12024-019-00098-2

14. Calmon MF, Tasso Mota M, Vassallo J, Rahal P. Penile carcinoma: risk factors and molecular alterations. Sci World J. 2011;11:269-282. doi:10.1100/tsw.2011.24

15. Martins FE, Rodrigues RN, Lopes TM. Organ-preserving surgery for penile carcinoma. Adv Urol. 2008;2008:1-7. doi:10.1155/2008/ 634216

16. Ajay Kumar J, Kumar S, Sinha AK. Evaluation of potential risk factors causing abdominal wound dehiscence. Acad J Surg. 2020;3:21-25. doi:10.47008/ajs/2020.3.1.5

17. Cheeti VS, Asha D, Raju B. Study of risk factors and management of abdominal wound dehiscence. Int J Contemp Med Surg Radiol. 2018;3:10-13. doi:10.21276/ijcmsr.2018.3.4.3

18. Sroczyński M, Sebastian M, Rudnicki J, Sebastian A, Agrawal AK. A complex approach to the treatment of fournier's gangrene. Adv Clin Exp Med. n.d.;22:131-135.

19. Rosa I, Guerreiro F. Hyperbaric oxygen therapy for the treatment of fournier's gangrene: a review of 34 cases. Acta Med Port. 2015;28:619. doi:10.20344/amp.6300

20. Schneidewind L, Anheuser P, Schönburg S, Wagenlehner FME, Kranz J. Hyperbaric oxygenation in the treatment of fournier's gangrene: a systematic review. Urol Int. 2021;105:247-256. doi:10.1159/ 000511615

21. Tutino R, Colli F, Rizzo G, et al. Which role for hyperbaric oxygen therapy in the treatment of fournier's gangrene? A Retrospective Study; 2020. doi:10.21203/rs.3.rs-60959/v1

22. Hung M-C, Chou C-L, Cheng L-C, et al. The role of hyperbaric oxygen therapy in treating extensive fournier's gangrene. Urol Sci. 2016;27:148-153. doi:10.1016/j.urols.2015.06.294

23. Zagli G, Cianchi G, Degl'Innocenti S, et al. Treatment of fournier's gangrene with combination of vacuum-assisted closure therapy, hyperbaric oxygen therapy, and protective colostomy. Case Rep Anesthesiol. 2011;2011:1-4. doi:10.1155/2011/430983
24. Pastore AL, Palleschi G, Ripoli A, et al. A multistep approach to manage fournier's gangrene in a patient with unknown type II diabetes: surgery, hyperbaric oxygen, and vacuum-assisted closure therapy: a case report. J Med Case Rep. 2013;7:1. doi:10.1186/1752-1947-7-1

25. Gandhi J, Seyam O, Smith N, Joshi G, Vatsia S, Khan S. Clinical utility of hyperbaric oxygen therapy in genitourinary medicine. Med Gas Res. 2018;8:29-33. doi:10.4103/2045-9912.229601

26. Oley MH, Oley MC, Noersasongko AD, et al. Effects of hyperbaric oxygen therapy on vascular endothelial growth factor protein and mRNA in crush injury patients: a randomized controlled trial study. Int J Surg Open. 2021;29:33-39. doi:10.1016/j.ijso.2021.01.003

27. Wilkinson HN, Hardman MJ. Wound healing: cellular mechanisms and pathological outcomes: cellular mechanisms of wound repair. Open Biol. 2020;10(9):200223. doi:10.20344/amp.6300

28. Qing C. The molecular biology in wound healing \& non-healing wound. Chin J Traumatol. 2017;20:189-193. doi:10.1016/j.cjtee.2017.06.001

29. Francis A, Baynosa RC. Hyperbaric oxygen therapy for the compromised graft or flap. Adv Wound Care. 2017;6:23-32. doi:10.1089/ wound.2016.0707

30. Jenwitheesuk K, Mahakkanukrauh A, Punjaruk W, et al. Degree of improvement after hyperbaric oxygen therapy for compromised flap and graft: a case series. Biomed Res. 2018;29(16). doi:10.4066/biomedicalresearch.29-18-663

31. Neheman A, Rappaport YH, Verhovsky G, et al. Hyperbaric oxygen therapy for pediatric "hypospadias cripple" - evaluating the advantages regarding graft take. J Pediatr Urol. 2020;16:163.e1-163.e7. doi:10.1016/j.jpurol.2020.01.002

32. Goerger E, Honnorat E, Savini H, et al. Anti-infective therapy without antimicrobials: apparent successful treatment of multidrug-resistant osteomyelitis with hyperbaric oxygen therapy. IDCases. 2016;6:60-64. doi:10.1016/j.idcr.2016.09.008

33. Mathieu D, Wattel F. Physiologic effects of hyperbaric oxygen on microorganisms and host defences against infection. Handb Hyperb Med. 2006;9781402044:103-119. doi:10.1007/1-4020-4448-8_7

34. Oley MH, Oley MC, Aling DMR, et al. Effects of hyperbaric oxygen therapy on the healing of thermal burns and its relationship with ICAM-1: a case-control study. Ann Med Surg. 2021;61:104-109. doi:10.1016/j.amsu.2020.12.025

35. Agha R, Ogawa R, Pietramaggiori G, Orgill DP. A review of the role of mechanical forces in cutaneous wound healing. J Surg Res. 2011;171:700-708. doi:10.1016/j.jss.2011.07.007

36. Landström JT, Schuyler RW, Macris GP. Microsurgical penile replantation facilitated by postoperative HBO treatment. Microsurgery. 2004;24(1):49-55. doi:10.1002/micr.10192

37. Zhong Z, Dong Z, Lu Q, et al. Successful penile replantation with adjuvant hyperbaric oxygen treatment. Urology. 2007;69(5):983.e3983.e5. doi:10.1016/j.urology.2007.02.024

38. Lu KB, Sanneic K, Stone JA, Morey A, Amirlak B. Success of penile replantation using combination of cialis, hyperbaric oxygen, and SPY technology. Eplasty. 2019;19:e2.
Research and Reports in Urology

\section{Publish your work in this journal}

Research and Reports in Urology is an international, peer-reviewed, open access journal publishing original research, reports, editorials, reviews and commentaries on all aspects of adult and pediatric urology in the clinic and laboratory including the following topics: Pathology, pathophysiology of urological disease; Investigation and treatment of urological disease; Pharmacology of drugs used for the treatment of urological disease. The manuscript management system is completely online and includes a very quick and fair peer-review system, which is all easy to use. Visit http://www.dovepress.com/ testimonials.php to read real quotes from published authors. 